\title{
Contribuições da fonologia de uso e da teoria dos exemplares para o estudo da monotongaçãa ${ }^{1}$
}

\author{
Contributions of phonology of use and the exemplar \\ theory to the study of monophthongization
}

Carine Haupt Fundação Universidade Federal do Tocantins

\section{Resumo}

Apresentamos um estudo sobre o fenômeno da monotongação dos ditongos decrescentes [aI , eI , OI , UI $]$ em sílabas abertas e fechadas na fala dos florianopolitanos com base nas entrevistas do banco de dados do VARSUL. Baseados na Fonologia de Uso e na Teoria de Exemplares, analisamos quantitativamente as ocorrências de monotongação, com o objetivo de verificar os efeitos da frequência de uso no fenômeno. Os nossos resultados apontam para dois efeitos da frequência de ocorrência: i) de processamento, resultando no apagamento da semivogal em palavras muito frequentes, até em alguns contextos desfavoráveis; ii) de armazenamento, que age em formas gramaticais irregulares com alta frequência no sentido de preservação do ditongo. Os fatores linguísticos, tais como tonicidade, extensão do vocábulo, estão atrelados ao fator palavra, corroborando um dos princípios da Fonologia de Uso, que dá à palavra o status de lócus da análise.

\section{Palavras-chave}

Monotongação, Fonologia de uso, Frequência de ocorrência, Exemplares 


\section{Abstract}

This is a study on the phenomenon of monophthongization in falling diphthongs [aI, $\mathrm{eI}, \mathrm{OI}, \mathrm{UI}$ ] within open and closed syllables in the speech of native speakers from Florianópolis as detected in interviews contained in VARSUL. Based on a UsedBased Model for Phonology and the Exemplar Theory, we analyze quantitatively the occurrence of monophthongization, in order to assess the effects of frequency of use of the phenomenon. Our results indicate two effects of token frequency: i) the processing effect, resulting in the deletion of the semi-vowel in very frequent words, even in unfavorable contexts; ii) the storage effect, which occurs in irregular grammatical forms with high frequency in order to preserve the diphthong. The linguistic factors such as stress and word length are linked to the word factor, confirming one of the principles of the Used-Based Model for Phonology, which gives to the word the status of locus of analysis.

\section{Keywords}

Monophthongization, Used-Based Model for Phonology, Token Frequency, Exemplars 


\section{Introdução}

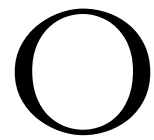

fenômeno da monotongação é um objeto já largamente estudado em diversas variedades do país. A maior parte desses estudos se concentra em modelos de fonologia tradicional e na Teoria da Variação, conforme proposta por Labov (1972). Assim, esses estudos acabam por concentrar-se no aspecto social da variação e da mudança linguística, buscando correlatos entre o fenômeno linguístico e as peculiaridades sociais da comunidade investigada. Como lacuna, não consideram as operações mentais envolvidas no armazenamento e no acesso às palavras no léxico mental dos falantes. O objetivo do presente trabalho, portanto, é apresentar um estudo que discuta essa questão, baseado na Fonologia de Uso e seu modelo representacional, a Teoria dos Exemplares.

A principal motivação para essa escolha foi a nossa crença de que os fenômenos fonéticos não são apenas simples variações que podem ser explicadas através de variáveis linguísticas e extralinguísticas, mas também parte inerente ao léxico e à constituição dos sistemas fonológicos. Abandonamos, portanto, a clássica divisão entre fonética e fonologia e passamos a adotar uma visão de interrelação, em que a fonologia de uma língua envolve a distribuição probabilística de variáveis, resultantes dos efeitos de frequência dos itens lexicais armazenados na memória de longo prazo, com todos os seus detalhes fonéticos. Dessa forma, o léxico deixa de ser considerado separadamente da gramática fonológica e a palavra passa a ser o lócus da categorização (CRISTÓFARO-SILVA, 2004).

Para realização desse estudo, utilizamos o banco de dados do VARSUL (Variação Linguística na Regiāo Sul do Brasil) e definimos, como objeto de análise, os ditongos decrescentes constituídos pela semivogal [Iㄱ] em sílabas abertas e fechadas pela fricativa sibilante, como os encontrados nas palavras caixa (['kaI $\left.\int e\right] \sim\left[\right.$ 'kaSe]) e depois ([de ' poI $\left.\int\right]$ [de 'poS)], ${ }^{2}$ respectivamente. Os dados são referentes a 24 informantes da cidade de Florianópolis, estratificados de acordo com os preceitos das regras variáveis de Labov. ${ }^{3}$ 
A descrição da pesquisa aqui apresentada é parcial, pois refere-se apenas à análise quantitativa, baseada na percepção. A essa análise soma-se um estudo acústico que visa verificar a gradiência no fenômeno que, por questões de espaço, não será descrito neste texto. Assim, para o presente trabalho, dedicamos, primeiramente, uma seção para apresentar alguns estudos já realizados sobre o assunto, com o objetivo de delimitar os contextos favoráveis e desfavoráveis ao fenômeno em estudo. Na seção seguinte, discutimos os pressupostos teóricos, relacionando-os com o nosso objeto de estudo. $\mathrm{Na}$ última seção, analisamos o fenômeno da monotongação sob o viés teórico da Fonologia de Uso e da Teoria dos Exemplares. Pela delimitação do espaço, apresentaremos os resultados de forma mais descritiva, evitando tabelas e detalhes das análises estatísticas. Encerramos o trabalho com nossas conclusōes.

\section{Monotongação: os estudos variacionistas}

É importante mencionar que todos os trabalhos descritos são de cunho sociolinguístico e usam como ferramenta estatística o pacote de programas VARBRUL (Variable Rules Analyses), que permite a análise de uma variável dependente binária (monotongação ou não) cruzada com diversas variáveis independentes e nos dá resultados referentes à ocorrência total, ao peso relativo em relação a cada variável independente e aos níveis de significância. A metodologia de análise desses estudos, resumidamente, consiste na análise de todas as variáveis (linguísticas e extralinguísticas) em testes de regressão que avaliam a probabilidade da ocorrência do fenômeno diante das muitas variáveis. Apresentamos, no Quadro 1, o resumo dos resultados de alguns estudos sobre o fenômeno da monotongação em sílabas abertas. Consideramos os trabalhos de Amaral (2005) no Rio Grande do Sul; Silva (2004) na Paraíba; Lopes (2002) no Pará; Araújo (1999) no Maranhão; Paiva (1996) no Rio de Janeiro e Cabreira (1996) nas três capitais da região Sul. Para o estudo em sílabas fechadas, consideramos a pesquisa de Brescancini (2009).

O Quadro 1 mostra que o contexto seguinte constituído de consoante palatoalveolar e tepe é fator foneticamente condicionante para o processo de monotongação em todos os estudos. No entanto, não há consenso entre os resultados em relação às outras variáveis, até porque nem todos os estudos consideram as mesmas e trabalham com todos os ditongos. É o caso da extensão 
do vocábulo e da classe de palavras, consideradas relevantes por apenas uma autora. Mas, mesmo em variáveis consideradas em todos os estudos como relevantes, ocorrem resultados diferentes: as sílabas tônicas se mostraram favorecedoras da monotongação nos estudos de Araújo (1999) e de Paiva (1996), porém, nos estudos de Amaral (2005) e de Silva (2004), foram as átonas que favoreceram o fenômeno. Em relação às variáveis sociais, parece haver um consenso nos resultados quando se trata da escolaridade, fator significativo mais recorrente nos trabalhos sobre monotongação. Quanto à idade, também não houve consenso e a variável sexo foi considerada relevante em apenas um estudo.

Em sílabas fechadas, temos o trabalho de Brescancini (2009). Essa autora fez seu estudo com base em dados de 72 informantes florianopolitanos. Desse número de informantes, 24 não produziram nenhum monotongo nos ditongos em questão, e, portanto, foram excluídos da análise. Os resultados foram, então, referentes a apenas 48 informantes. Segundo a autora, houve concentração de monotongação em itens específicos, a saber, mais, depois, dois e seis, e, recorrentemente, diante da realização palatoalveolar da fricativa final. ${ }^{4}$

Brescancini (2009), analisando as variáveis linguísticas e sociais, obteve, como estatisticamente relevantes, o papel morfológico de /S/ e o sexo. A redução foi favorecida quando a fricativa final fazia parte da flexão de verbo, como em vais. Como flexão nominal, no entanto, a redução do ditongo foi desfavorecida. Os radicais tiveram comportamento neutro, ou seja, não podem ser considerados nem favorecedores nem desfavorecedores. Em relação ao sexo, as mulheres mostraram um comportamento favorável à redução, enquanto os homens não. A seguir, a autora ainda cruza a variável sexo com escolaridade e idade e chega à conclusão de que a escolaridade não interfere no fenômeno e que os jovens se mostram menos propensos à monotongação. A autora conclui o trabalho dizendo que "a redução do ditongo decrescente diante /S/ caracteriza-se como um processo condicionado lexicalmente, mas que ainda apresenta resquícios de condicionamento estrutural, especificamente de cunho morfológico" (BRESCANCINI, 2009, p. 49).

Com base nos resultados referentes às variáveis linguísticas nos estudos descritos nesta seção, podemos considerar que há motivação fonética na redução do ditongo em sílabas abertas quando este for seguido de tepe e consoante palatoalveolar. ${ }^{5}$ Os demais contextos seguintes parecem não apresentar as mesmas condiçôes. A respeito das outras variáveis linguísticas, como tonicidade, extensão 
vocabular, status morfológico, não assumimos nenhuma posição, pois lembramos que, na perspectiva da Fonologia de Uso, partimos das hipóteses de que o uso afeta as representações mentais e de que o fenômeno da monotongação está sujeito aos efeitos de processamento e de armazenamento e, portanto, é a palavra o lócus de análise e não os fatores isolados. Assim, essas características estruturais estarão atreladas às palavras em que houver monotongação.

Em relação à monotongação em sílabas fechadas, já percebemos o peso do item lexical no fenômeno, o que nos leva à hipótese de que o fenômeno não atinge todos os itens lexicais com o mesmo contexto. Para aprofundar nossas hipóteses e explicar as discrepâncias de resultados entre os diversos estudos apresentados, precisamos, antes, conhecer os pressupostos das teorias da Fonologia de Uso e dos Exemplares, apresentadas a seguir.

\section{A Fonologia de Uso e a Teoria dos Exemplares}

O modelo da Fonologia de Uso deriva de uma abordagem que visa abarcar todos os subsistemas (fonologia, sintaxe, semântica) em uma teoria da linguagem. Nessa teoria de linguagem, estudar somente as estruturas não é o suficiente.

[...] the focus on structure needs to be supplemented with a perspective that includes more than just structure, a view that includes two other important aspects of the language phenomenon - the material content or substance of language, and language use. (BYBEE, 2001, p. 2)

O conteúdo material ou a substância da língua se refere à fonética e à semântica. $\mathrm{O}$ uso da língua, por sua vez, inclui todo o processamento, assim como as interações sociais. Dessa forma, nessa proposta, a frequência com que uma determinada palavra ou estrutura é usada pode ter impacto na sua estrutura fonológica, isto é, a experiência afeta a representação, de modo que a força lexical de uma palavra pode mudar à medida que é mais ou menos usada em diferentes contextos. As representações mentais dos objetos linguísticos, por sua vez, têm as mesmas propriedades das representações mentais de outros objetos e são categorizadas da mesma forma. Essa categorização é baseada em similaridades em diferentes níveis. Ainda de acordo com esse modelo, temos as generalizações que emergem das representações armazenadas, isto é, a organização lexical fornece 
generalizações e segmentações para os vários graus de abstração e generalidade, uma vez que unidades tais como morfema, segmentos ou sílabas emergem das relações de similaridade que organizam as representações.

Assim, considerando os princípios apresentados por Bybee (2001), assumimos que o uso real das unidades linguísticas interage com a substância, ou seja, com a forma e o sentido, agindo sobre a estruturação mental da língua. Dessa maneira, o uso repetido de um monotongo em detrimento do ditongo acarretará mudança na representação mental das palavras em que ocorre. É com base nesse pressuposto que discutimos, partindo da análise dos dados, como se estabelecem as redes de similaridade fonética e semântica entre as palavras com ditongos e que generalizaçôes podem emergir delas.

A frequência e o uso na língua, como mencionado anteriormente, têm papel crucial nesse modelo. No que tange à Fonologia de Uso e às variações e mudanças sonoras, temos duas categorias de frequência: a frequência de ocorrência e a frequência tipo. A primeira refere-se à ocorrência de determinado item lexical em um corpus, enquanto a última se refere a um padrão na língua. Em relação à frequência de ocorrência, temos de considerar que ela pode exercer diferentes efeitos, dependendo das características do fenômeno. Segundo Phillips (1984), há mudanças que afetam primeiramente as palavras mais frequentes e outras que afetam primeiramente as menos frequentes. De acordo com essa autora, as mudanças foneticamente motivadas, ou seja, aquelas que têm base na fisiologia da fala, atingem, em primeiro lugar, as palavras mais frequentes. Entre esses fenômenos, encontram-se os casos de redução, apagamento e assimilação.

Quando a variação afeta primeiramente as palavras menos frequentes, podemos ter um caso de analogia (HOOPER, 1976), em que formas infrequentes seguem o paradigma das formas frequentes. Ou podemos estar diante de mudanças que produzem novas restrições no sistema da língua e que não têm motivação fonética. Phillips (2001) explica que essas mudanças sonoras atingem primeiramente as palavras menos frequentes, porque elas requerem análise, seja ela sintática, morfológica ou fonológica. Em Phillips $(1984,2001)$ encontramos vários casos em que a reanálise ocorre primeiramente nas palavras menos frequentes. Citamos o exemplo do apagamento do glide, no inglês médio, no qual ocorreu uma mudança nas restrições fonotáticas que foi além de uma mudança na superfície fonética (PHILLIPS, 1984). De acordo com a autora, não havia contexto fonético propício para esse apagamento. Ele ocorreu em sílabas iniciais 
tônicas, em que se espera um fortalecimento, e não era resultado de uma assimilação. O levantamento feito pela autora confirma sua hipótese: as palavras menos frequentes mudaram primeiro nesse caso.

Em se tratando de monotongação, nosso objeto de estudo, temos um caso de redução, uma variação de superfície fonética. Os estudos variacionistas a respeito da monotongação confirmam a motivação fonética no fenômeno, uma vez que os contextos favorecedores são aqueles em que os ditongos são seguidos de consoante fricativa palato-alveolar ou de tepe. Assim, lançamos a hipótese de que as palavras mais frequentes são atingidas com mais intensidade. No entanto, os estudos variacionistas também atestam a ocorrência de monotongação em outros contextos, em palavras como reino e leite. Esses casos de monotongação não são em número expressivo, e esses contextos acabam sendo classificados como não favorecedores, uma vez que, em termos estatísticos, a probabilidade de ocorrer a monotongação é muito baixa. Esses casos se enquadrariam naqueles que atingem primeiramente as palavras com frequência de ocorrência baixa, uma vez que não têm motivação na fisiologia da fala?

Bybee (2003) apresenta ainda outro efeito da frequência. Segundo ela, os itens frequentes, paradoxalmente, desencadeiam mudanças e, ao mesmo tempo, preservam formas. Bybee (2003) afirma que as mudanças costumam ser de forma e de significado, enquanto a preservação se dá em nível morfossintático. São os efeitos de processamento que resultam na automatização da fala versus os efeitos de armazenamento. Assim, estruturas morfológicas de palavras e propriedades sintáticas de construções, quando muito frequentes, passam a se fortalecer e são preservadas. Um bom exemplo disso são algumas formas irregulares de verbos muito frequentes, como o verbo ser.

Além da frequência de ocorrência, como já mencionado, temos também a frequência tipo. A frequência tipo é a frequência de um padrão no léxico, referese à frequência de dicionário, como um afixo ou desinência. Portanto, está associada à produtividade de determinado padrão e é usada para outros tipos de análises, por exemplo, referentes às generalizações fonotáticas. Resumidamente, podemos dizer que a alta frequência tipo garante que uma determinada construção seja usada frequentemente, fortificando seu esquema representacional, tornando-a mais acessível para o uso em novos itens. Já a frequência de ocorrência promove o fortalecimento e a conservação de formas irregulares e idiomáticas, que só poderiam sobreviver por causa de sua alta frequência (BYBEE, 2003), e as 
mudanças fonéticas e semânticas, atingindo primeiramente palavras muito frequentes, quando foneticamente motivadas, e as menos frequentes (PHILLIPS, 1984) quando tiverem outras motivações, que não fisiológicas.

No caso do fenômeno da monotongação, analisamos os efeitos da frequência de ocorrência, como já mencionado, a fim de testar a hipótese de que as palavras mais frequentes monotongam em maiores proporções, uma vez que os contextos adjacentes parecem ter influência sobre o fenômeno. Em relação à frequência tipo, fazemos um levantamento dos padrões relativos aos fatores estruturais citados nos estudos variacionistas - tonicidade, posição da sílaba em que se encontra o ditongo, extensão do vocábulo, status morfológico, contexto fonético seguinte - que poderá nos auxiliar no entendimento do fenômeno da monotongação.

Outra questão pertinente a nossa análise refere-se aos contextos alternativos e uniformes (BYBEE, 2002). Os contextos uniformes são aqueles que sempre estão presentes em cada palavra e, portanto, encontram-se no interior dela. Desse modo, morfemas que apresentam o contexto uniforme para a mudança/variação e são muito frequentes podem acarretar maior número de ocorrências do fenômeno ao qual o morfema está sujeito, ou até conduzir mais rapidamente a uma mudança. Os contextos alternativos, por sua vez, são aqueles que podem ou não estar presentes na palavra e podem ser internos ou externos a ela. Os últimos são os contextos que iniciam a palavra seguinte. Às vezes, um fenômeno pode afetar um afixo numa determinada palavra e não afetar o mesmo afixo em outra devido ao contexto alternativo.

Em nosso estudo, pretendemos avaliar o efeito dos contextos uniformes e alternativos. Consideramos como contextos uniformes aqueles presentes de maneira regular nos sufixos, como o tepe em-eiro, e os demais contextos seguintes internos à palavra nos radicais. Uma observação faz-se necessária neste momento: esses contextos seguintes internos também podem ser entendidos como contextos alternativos, uma vez que o ditongo terá, em cada item lexical, um contexto específico. No entanto, quando encontrados no radical, as possíveis derivações (ou flexões) acabam tendo o mesmo contexto (por exemplo, deixar, deixamos, maior, maiores, coisa, coisinha). Dessa forma, consideramos como contextos alternativos apenas aqueles externos à palavra. Esses contextos podem, por sua vez, ser esclarecedores para a monotongação de ditongos que se encontram em sílabas finais de palavras. A desinência verbal -ei, por exemplo, 
terá a semivogal apagada quando o contexto seguinte for foneticamente propício, como uma fricativa palatoalveolar? E os ditongos em sílabas fechadas, como mais? Como agiriam os contextos seguintes $[S, \mathrm{~s}, \mathrm{a}]$ nas sequências mais chato, mais cedo e mais amigo na monotongação dessa palavra?

Como modelo representacional para a Fonologia de Uso, temos a Teoria dos Exemplares (JOHNSON, 1997; PIERREHUMBERT, 2000). Segundo essa teoria, todas as amostras são armazenadas e categorizadas, criando, assim, categorias que representam as variaçóes encontradas no uso e no processamento da língua. As palavras são armazenadas em redes que mapeiam relações de similaridade em todos os níveis e as palavras com mais similaridades são armazenadas em nuvens. Exemplares mais frequentes tornam-se mais fortes, os menos frequentes enfraquecem e, com o tempo, deixam de ser usados. Na seção a seguir, averiguaremos como se organizam as nuvens de exemplares das palavras com os ditongos em estudo.

\section{A monotongação na perspectiva da Fonologia de Uso e da Teoria dos Exemplares}

A análise da frequência de ocorrência foi precedida de um levantamento da frequência tipo. Esse levantamento foi feito no corpus de língua escrita do NILC (Núcleo Interinstitucional de Linguística Computacional) e os tipos encontrados foram distribuídos de acordo com as diversas características estruturais em que os ditongos se encontravam, relativos à tonicidade, posição da sílaba na palavra, contexto seguinte, extensão do vocábulo e status morfológico.

Através desse levantamento, constatamos padrōes distintos para os tipos com ditongos em sílabas fechadas e em sílabas abertas referentes ao status morfológico, à tonicidade e à posição silábica. Os ditongos em sílabas fechadas encontram-se sempre em final de palavra (com exceção da palavra quaisquer) e predominantemente com função de sufixo (desinência verbal e nominal), enquanto os ditongos em sílabas abertas se distribuem em diferentes posições silábicas e concentram-se no radical da palavra, com exceção do ditongo [e I] $]$, para o qual há um elevado número de tipos como sufixos, devido ao sufixo -eiro e à desinência verbal -ei.

Quanto à tonicidade, podemos estabelecer uma relação com o fator status morfológico: a) sufixos: as desinências verbais são tônicas; as desinências 
nominais de número são tônicas para os ditongos [aI ] e átonas para o ditongo [eI] ] b) radicais: os ditongos são, na maior parte das vezes, átonos. Assim, em sílabas fechadas, há predomínio de tipos com ditongo tônico para [aI ] e [OI] e átono para [eI]; e, em sílabas abertas, há um maior número de ditongos [eI] tônicos, ditongos [oI] átonos e uma distribuição equilibrada para o ditongo [aI] (como consequência da desinência verbal tônica em amai, por exemplo, e do radical átono em palavras como caixa).

Outra diferença entre os ditongos em sílabas abertas e fechadas refere-se ao contexto seguinte. As sílabas fechadas estão sujeitas às influências dos contextos alternativos das palavras seguintes, enquanto as sílabas abertas apresentam contextos internos diversos. Com base no levantamento feito, podemos prever, por exemplo, um maior número de monotongações (em percentuais) para o ditongo [e $\mathrm{I}$ ] do que para o ditongo [oI $\mathrm{I}_{\text {n }}$, uma vez que este último apresenta mais tipos com ditongo seguido de vogal e oclusiva (os dois contextos somam $71,52 \%$ dos tipos), contextos não propícios para a monotongação, conforme atestam os estudos acerca do fenômeno. Essas diferenças nos levaram a analisar cada ditongo separadamente, em sílabas abertas e fechadas, considerando a frequência de ocorrência e a frequência tipo, quando necessário. Após essa análise, reunimos as conclusões que seguem.

Conforme os estudos mencionados na seção anterior, os contextos seguintes de tepe e fricativa palatoalveolar são os contextos favorecedores para a monotongação em sílabas abertas. Constatamos que a monotongação ocorre em todos os itens lexicais com esse contexto para os ditongos [aI $]$ e [eI $]$, independentemente da frequência de ocorrência, isto é, não conseguimos mais visualizar o efeito de frequência (a relação entre a frequência e a monotongação não foi significativa), uma vez que o fenômeno já está amplamente difundido nos contextos favorecedores. Para ilustrar esse fato, apresentamos a Tabela 1, na qual listamos várias palavras com frequências de ocorrência diferentes e os respectivos casos de monotongação. A Teoria dos Exemplares contribui para um entendimento melhor desse fenômeno: as nuvens de exemplares com o monotongo são mais robustas do que as com o ditongo. Lembramos que, segundo Bybee (2001), as generalizações emergem diretamente das representaçōes armazenadas. Assim, com mais formas com monotongo armazenadas, o falante generaliza o seu uso para todos os itens lexicais em que se poderia ter um ditongo seguido de $[S]$ e $[\varsigma]$. 
O fato de não percebermos mais os efeitos da frequência de uso nos casos anteriormente descritos pode indicar que o fenômeno está em estágio avançado quando em sílabas abertas seguidas de $[S]$ e $[\varsigma]$. Certamente, um próximo passo seria fazer um estudo longitudinal e com diferentes faixas etárias para averiguar se temos uma mudança em curso. Ademais, os poucos casos de preservação do ditongo podem estar associados ao fato de o ditongo existir na escrita. Certamente, para confirmar essa tendência, cabem estudos mais aprofundados, nos quais a variável escolaridade deve ser considerada. No entanto, alguns estudiosos já discutiram essa questão, entre eles Paiva (2003). A respeito

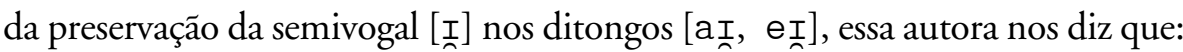

O comportamento linguístico do indivíduo sofre mudanças ao longo de sua vida para se ajustar aos diferentes momentos etários e às pressões sociais a que tem que fazer face em diferentes momentos de sua vida. Não está excluída, no entanto, a possibilidade de que essas mudanças reflitam também maior processo de escolarização e um maior contato com a forma escrita da língua em que a semivogal anterior é preservada (PAIVA, 2003 apud CRISTÓFARO-SILVA; GRECO, 2010, p. 89).

Nos demais contextos fonéticos, aqueles considerados desfavorecedores pelos resultados dos estudos variacionistas acerca do fenômeno, também ocorrem monotongações, ou seja, a variação é possível. No entanto, o número de monotongações é reduzido, o que nos mostra haver um maior de número de exemplares para a categoria de ditongo do que para a de monotongo. Constatamos que a alta frequência de ocorrência pode estar motivando a monotongação em itens lexicais que não apresentam contexto fonético propício, como é o caso das palavras meio, maior, coisa e de chunks, ${ }^{6}$ como pois é. Trata-se do efeito de processamento, resultando na automatização de um item muito recorrente. Podemos considerar também o peso da familiaridade que o falante tem com essas palavras como fator que contribui para a redução.

Além das monotongaçôes nesses itens lexicais com alta frequência de ocorrência, temos ainda ocorrência de monotongação em palavras com frequência de ocorrência baixa e sem contexto favorável para a monotongação. É o que acontece com as palavras ajeitadinho, amanteigado, teimar, queimar, queimado, 
queimadura e treinamento. Podemos visualizar o efeito da frequência tipo na monotongação nessas palavras (com exceção do item lexical ajeitadinho), tendo em vista que os tipos com ditongos seguidos dos contextos de consoantes nasais e oclusiva velar não são muito recorrentes na língua. Dessa forma, o falante usa o padrão mais recorrente, ou seja, os monotongos seguidos desses contextos, como os encontrados nas palavras [ ' S ege] e [d3i ' leme]. ${ }^{7}$

Além disso, observamos também a monotongação em monossílabos com alta frequência de ocorrência, porém em baixas proporçōes, como em fui levar - [fule 'va]. Com exceção da palavra pai, todas os demais monossílabos com alta frequência de ocorrência são formas verbais. As palavras vai, sei, foi e fui são formas verbais irregulares - morfemas gramaticais - e se fortalecem com a repetição. Podemos dizer que, no caso dos monossílabos, vemos um dos efeitos da repetição das palavras (BYBEE, 2003): o efeito de armazenamento nos ditongos em formas verbais irregulares em sílabas abertas, fortalecendo a autonomia lexical dessas palavras. Para explicar os poucos casos de monotongação nesses monossílabos, recorremos ao contexto alternativo. Em muitos casos, temos que o monossílabo é seguido de uma palavra que se inicia com uma vogal homorgânica à semivogal, resultando em sândi, decorrente de chunks, como vai indo, fui indo e foi embora.

No entanto, ao considerarmos o ditongo [ $\mathrm{e} I$ ] , encontramos outros contextos alternativos associados às monotongações nos monossílabos e também em palavras mais extensas, referentes às formas verbais, como levei. $\mathrm{O}$ interessante é que esses contextos não são aqueles considerados favorecedores sob o aspecto de contextos uniformes, como as fricativas palatoalveolares. As monotongaçôes ocorreram predominantemente $(71,5 \%)$ diante de vogais, como [a, o], por exemplo, em falei alto - [fale ' aưt $\mathrm{v}$. Assim como ocorreu a monotongação em meiola, que é uma palavra com alta frequente de ocorrência, observamos uma tendência de monotongação dos verbos terminados em -ei quando seguidos de vogal. Como contextos alternativos mais frequentes para o ditongo [e $\mathrm{e}$ ] em sílabas abertas finais, temos o contexto vocálico e o de consoante oclusiva. Este último contexto parece inibir a monotongação enquanto o contexto alternativo vocálico favorece o fenômeno, como consequência da automatização, especialmente se esses itens lexicais se encontrarem em construções maiores, nas quais a sílaba final do verbo perde a tonicidade, tornando-se mais propensa à redução. 
Verificamos ainda que as monotongações do ditongo [eI] em sílabas finais ocorreram em maiores proporções nos verbos mais frequentes, sugerindo, assim, que o contexto vocálico apresenta condições para a redução do ditongo. O Gráfico 1 mostra que as palavras com frequência de ocorrência mais alta tiveram um número maior de monotongações do que as palavras menos frequentes. Como exceção, temos a palavra falei ( 58 ocorrências e 2 monotongações). No entanto, se observamos o contexto alternativo desse verbo, encontramos uma explicação: a palavra falei é seguida de consoante oclusiva em 31 das 59 ocorrências. Vimos que o contexto alternativo de consoante oclusiva não é propício para a monotongação. Assim, aquelas palavras que se encontram em contextos mais frequentes para a monotongação, monotongam mais.

Por fim, temos a expansão do fenômeno de monotongação para as sílabas fechadas. Consideramos o fenômeno nessas sílabas como decorrente da generalização das monotongações que ocorrem em sílabas abertas seguidas de consoante palatoalveolar. $\mathrm{O}$ fenômeno está, portanto, associado ao fenômeno de palatalização da fricativa final, que resulta em contexto propício para a monotongação. Assim, a mesma redução que ocorre em sílabas abertas decorrente da sobreposição de gestos articulatórios da semivogal e da consoante palatoalveolar passa a ocorrer nas sílabas fechadas. O Gráfico 2 confirma essa relação.

Em relação aos contextos alternativos que seguem os ditongos em sílabas fechadas, constatamos que o contexto que mais favorece a monotongação é o de consoante oclusiva, seguido do contexto de pausa, da consoante fricativa e de consoante lateral, essa última com poucas ocorrências. Esses são os contextos em que também ocorre o maior número de palatalização. Assim, com base nessa constatação, concluímos que a palatalização da fricativa final é um fator condicionante para a monotongação.

Além disso, a frequência de ocorrência também desempenha o seu papel nas monotongações em sílabas fechadas, já que o fenômeno é foneticamente motivado nessas sílabas devido à palatalização da fricativa final. As palavras com baixa frequência de ocorrência são, quase em todos os casos, aquelas em que o ditongo se encontra na desinência de plural e a taxa de monotongação é baixa. As ocorrências dos itens lexicais com ditongos em sílabas fechadas são apresentadas no Gráfico 3. As palavras estão assim divididas: com alta frequência de ocorrência (mais de 100 ocorrências) e com frequência moderada e baixa 
(menos de 100 ocorrências). ${ }^{7}$ Vemos que as monotongações se concentram nos itens lexicais com frequência de ocorrência mais alta.

Observamos três casos de discrepância no Gráfico 3: as palavras pais, pois e jamais. Em relação à palavra pais, podemos estabelecer uma relação com o que acontece com essa palavra no singular. Pai teve apenas uma monotongação num total de 306 ocorrências. Isso mostra que a nuvem de exemplares com a semivogal é bastante forte, o que se reflete na forma plural, mesmo que esta possa apresentar características fonéticas similares a mais, por exemplo. A palavra jamais, por sua vez, apresenta similaridade fonética com a palavra mais, que teve alta frequência de ocorrência e 44,3\% de monotongação, o que explica que jamais, mesmo tendo baixa frequência de ocorrência, também monotongasse. A palavra pois teve poucos casos de palatalização da fricativa final, devido ao chunk [poi $\| z \varepsilon$ ], do qual resulta um contexto não propício para a monotongação. Todas essas considerações nos levam a assumir que a frequência de uso dos itens lexicais tem seu papel na monotongação. Com a Teoria dos Exemplares, é possível entender como a frequência de uso atinge as palavras e influencia nas mudanças sonoras. Num modelo de exemplares, cada nova amostra é categorizada através da avaliação do item a ser categorizado em relação ao conjunto de exemplares já existente. De acordo com Pierrehumbert (2000), para classificar uma nova amostra, o rótulo mais provável entre os rótulos dos exemplares vizinhos é computado. Para aplicar isso à nossa pesquisa, consideremos os rótulos [aI ] e [a]. Imaginemos uma nova amostra que se encontra entre essas duas categorias. Caso tenhamos mais exemplares ativados com ditongo do que com monotongo, a nova amostra será classificada como ditongo. Temos, portanto, a influência da frequência na categorização de novas amostras.

Essa explicação se refere ao que acontece na percepção. Na produção, a decisão de produzir uma determinada categoria (ditongo ou monotongo, por exemplo) é realizada através da ativação do rótulo correspondente. A seleção de um alvo fonético, dado o rótulo, pode ser modelada como uma seleção randômica de um exemplar de uma nuvem de exemplares associada com o rótulo em questão. Um rótulo com número maior de exemplares na vizinhança de uma amostra tem vantagem na competição e será mais facilmente acessado. Pierrehumbert (2000) também nos apresenta um modelo de produção em que explica a tendência de diminuição dos alvos articulatórios, a fim de poupar esforço e acelerar a comunicação. Nesse modelo, cada amostra é produzida 
levemente enfraquecida se comparada com o exemplar da categoria que foi aleatoriamente selecionada como a meta da produção. Assim, a tendência sistemática de enfraquecimento causa a distribuição de exemplares para a mudança. Provavelmente é isso que acontece com os ditongos, para os quais encontramos o monotongo. A semivogal está enfraquecendo, reduzindo-se a uma zona de transição até ser apagada.

Assim, podemos dizer que a frequência está diretamente relacionada com essas taxas de enfraquecimento. Considerando que palavras muito frequentes são mais usadas do que as pouco frequentes, suas representações de exemplares refletem um número maior de impactos na tendência em direção ao enfraquecimento. Como resultado, elas irão enfraquecer mais rapidamente do que as palavras menos frequentes. Explica-se, portanto, por que as palavras com frequência de ocorrência mais alta tendem a ser afetadas primeiramente e em maiores taxas nos fenômenos de redução foneticamente motivados.

\section{Conclusão}

Considerando o papel dos efeitos da frequência de ocorrência e da frequência tipo na monotongação dos ditongos [aIn, eI I, OI , $\mathrm{UII}_{\text {I }}$, concluímos que a redução da magnitude dos gestos ocorre com itens lexicais com alta frequência de ocorrência, mesmo em contextos não propícios. Verificamos, também, em sílabas fechadas (mais) e abertas finais (comecei), esse efeito, uma vez que itens lexicais mais frequentes monotongaram mais. Além disso, a frequência dos contextos alternativos também desempenha seu papel: o contexto alternativo vocálico, que favoreceu a monotongação do ditongo [e $\mathrm{I}] \mathrm{em}$ formas verbais, teve alta frequência de ocorrência, enquanto o de consoante palatoalveolar, contexto propício para a monotongação do mesmo ditongo em sílabas iniciais e mediais, teve baixa frequência de ocorrência. Ademais, é nos ditongos em sílabas fechadas que melhor visualizamos o condicionamento lexical do fenômeno. As palavras pouco frequentes e que carregam informação morfossintática, como as palavras no plural, monotongaram menos. A mesma tendência de preservação do ditongo que carrega informação morfossintática foi observada nos monossílabos vai, sei, foi e fui, estes, porém, com alta frequência de ocorrência. Por outro lado, houve também a monotongação em itens lexicais com baixa frequência de ocorrência. Nesses casos, podemos considerar que são 
itens lexicais suscetíveis à reanálise ou que o fenômeno é condicionado pela frequência tipo, pois os ditongos naquelas estruturas são tipos pouco frequentes na língua, prevalecendo, assim, o monotongo, padrão mais recorrente nesses contextos.

Em ambos os casos, em palavras com alta e baixa frequência de ocorrência, o modelo da Fonologia de Uso e da Teoria dos Exemplares evidencia que é possível analisar o fenômeno da monotongação considerando o item lexical como lócus. Assim, esperamos ter contribuído para o entendimento do apagamento da semivogal [I] em ditongos decrescentes no dialeto florianopolitano. Estudos com a expansão do objeto de análise, abordando, por exemplo, as variáveis sociais e os ditongos decrescentes nasais, bem como o estudo da monotongação em outras variedades do $\mathrm{PB}$ podem enriquecer $\mathrm{o}$ quadro apresentado aqui.

\section{Notas}

${ }^{1}$ Neste trabalho, apresento parte dos resultados da pesquisa desenvolvida durante meu doutoramento pelo Programa de Pós-Graduação em Linguística da Universidade Federal de Santa Catarina. Agradeço, portanto, ao meu orientador Prof. Dr. Marco Antônio Esteves da Rocha e à minha coorientadora Profa. Dra. Izabel Christine Seara pelas valiosas contribuições.

${ }^{2}$ A pronúncia palatalizada da consoante fricativa final é bastante recorrente em Florianópolis (BRESCANCINI, 1996; HAUPT, 2006). Há poucos estudos sobre monotongação em sílabas fechadas e essa escassez pode estar ligada ao fato de este ser um fenômeno recorrente em Florianópolis, mas não noutras regiōes.

${ }^{3}$ Maiores informações sobre o Varsul estão disponíveis no sítio www.cce.ufsc.br/ -varsul

${ }^{4}$ Nesse estudo, houve apenas 10 ocorrências de monotongação diante de fricativa alveolar.

${ }^{5}$ Quando o ditongo é seguido de consoante palatoalveolar, temos um caso de assimilação, uma vez que tanto semivogal quanto fricativas palatoalveolares compartilham o traço [+alto]. 
${ }^{5}$ Chunk é uma sequência de palavras que é interpretada pelos falantes como uma única unidade e que pode, assim, sofrer as mesmas generalizaçôes que as palavras, que são o lócus da análise fonológica no modelo da Fonologia de Uso.

${ }^{7}$ Um rápido levantamento desse padrão nos dados do NILC resultou em mais de 1000 entradas.

8 'Porcentagem' foi o critério usado para definir se o item lexical era frequente ou não em ambos os corpora (NILC e VARSUL). Os dados foram divididos em três grupos: aqueles com alta frequência de ocorrência (palavras com até $1 \%$ de ocorrência do total das palavras com ditongo), com frequência moderada (palavras entre $1 \%$ e $0,1 \%$ do total das palavras com ditongo) e com baixa frequência (palavras com menos de $0,1 \%$ de ocorrência em relação ao total das palavras com ditongo). No caso dos dados apresentados no Gráfico 3, tivemos palavras com alta frequência de ocorrência (mais de 1\%, o que resultou em itens lexicais com mais de 100 ocorrências) e palavras com frequência moderada (entre $1 \%$ e $0,1 \%$, o que resultou em palavras entre 11 e 75 ocorrências). Como pouco frequentes, tivemos as palavras vais (10 ocorrências) e jamais (8 ocorrências). Maiores detalhes sobre o levantamento dos dados é possível encontrar no link http://www.tede.ufsc.br/teses/PLLG0470-T.pdf .

\section{Referências}

AMARAL, M P. Ditongos variáveis no sul do Brasil. Letras de Hoje. Porto Alegre, v. 40, n. 3, p. 101-106, set. 2005.

ARAÚJO, M. F. R. A alternância de [eI ] - [e] no português falado na cidade de Caxias, Maranhão. 1999. 138f. Dissertação (Mestrado em Linguística) Instituto de Estudos de Linguagem, Unicamp, Campinas, 1999.

BRESCANCINI, C. A palatalização da fricativa alveolar não morfêmica em posição de coda no português falado em três regiōes de influência açoriana no município de Florianópolis. 1996. 219 f. Dissertação (Programa de Pós-Graduação em Linguística) - Centro de Comunicação e Expressão, UFSC, Florianópolis, 1996.

BRESCANCINI, C. A redução de ditongos decrescentes seguidos por fricativa em coda no açoriano-catarinense. In: BISOL, Leda; COLLISCHONN, Gisela (Org.). Português do sul do Brasil: variação fonológica. Porto Alegre: Edipucrs, 2009. p. 34-49. 
BYBEE, J. Phonology and language use. Cambridge University Press, 2001. 238p. BYBEE, J. Mechanisms of change in grammaticization: the role of frequency. In: JOSEF, B. D.; JANDA, J. (Ed.). The handbook of Historical Linguistic. Oxford: Blackwell, 2003. p. 603-623.

BYBEE, J. Word frequency and context of use in the lexical diffusion of phonetically conditioned sound change. Language Variation and Change. Cambridge University Press, n. 14, p. 261-290, 2002.

CABREIRA, S. H. A monotongação dos ditongos orais decrescentes em Curitiba, Florianópolis e Porto Alegre. 1996. 115f. Dissertação (Mestrado em Letras (Linguística Aplicada)). PUC/RS, Porto Alegre, 1996.

CRISTÓFARO-SILVA, Thaïs. A aquisição de padrões sonoros variáveis. Letras de Hoje. Porto Alegre, v. 39, n. 3, p. 101-110, set. 2004.

CRISTÓFARO-SILVA, Thaïs; GRECO, Amana. Representações fonológicas: contribuição da oralidade e da escrita. Letras de Hoje, Porto Alegre, v. 45, n. 1, p. 87-93, jan/mar, 2010.

HAUPT, C. Sibilantes coronais - o processo de palatalização e a ditongação em silabas travadas na fala de florianopolitanos nativos: uma análise baseada na fonologia da geometria de traços. 2006. 111f. Dissertação (Mestrado em Linguística) Programa de Pós-Graduação em Linguística, UFSC, Florianópolis, 2006.

HOOPER, J. B. An introduction to natural generative phonology. New York: Academic Press, 1976. 254p.

JOHNSON, K. The auditory/perceptual basis for speech segmentation. OSU Working Papers in Linguistic, n. 50, p. 101-113, 1997.

LABOV, W. Sociolinguistic pattern. Philadelphia, PA: University of Pensilvania Press, 1972. 362p.

LOPES, R. A realização variável dos ditongos /ow/ e lej/ no português falado em Altamira/PA. 2002. 97 f. Dissertação (Curso de Pós-Graduação em Letras/ Mestrado em Linguística) - Centro de Letras e Artes, UFP, Belém, 2002.

PAIVA, M. C. A. Supressão das semivogais nos ditongos crescentes. In: SILVA, G. M. de O.; SCHERRE, M. M. P. (Ed.). Padröes sociolinguisticos: análise de fenômenos variáveis na cidade do Rio de Janeiro. Departamento de Linguística e Filologia da UFRJ. Rio de Janeiro: Tempo Brasileiro, 1996. p. 219-333. 
PAIVA, M. C. A. O percurso da monotongação [ey]: observações no tempo real. In: PAIVA, M. C.; DUARTE, M. E. (Ed.). Mudança linguística em tempo real. 2003. p. 31-46.

PHILLIPS, B. Word Frequency and the Actuation of Sound Change. Language, v. 60, n. 2, p 320-342, jun. 1984.

PHILLIPS, B. Lexical diffusion, lexical frequency and lexical analysis. In: BYBBE, J., HOPPER, P. (Ed.). Frequency and the emergence of linguistic structure. John Benjamins Publishing, Co, 2001. p. 123-136.

PIERRENHUMBERT, J. Exemplar Dynamics: Word frequency, lenition and contrast. In BYBEE, J.; HOPPER, P. (Ed.). Frequency and the emergence of linguistic structure. Amsterdam: Benjamins, 2000. p. 123-136.

SILVA, F. S. O processo de monotongação em João Pessoa. In: HORA, D. da (Ed.). Estudos Sociolinguísticos: perfil de uma comunidade. Santa Maria: Palloti, 2004. p. 29-43. 


\section{ANEXOS}

\section{QUADRO 1}

Resumo das variáveis envolvidas no fenômeno da monotongação em estudos já realizados

\begin{tabular}{|c|c|c|}
\hline Fator & & $\begin{array}{l}\text { Considerações (favorável ou desfavorável à } \\
\text { monotongação) }\end{array}$ \\
\hline $\begin{array}{l}\text { Contexto } \\
\text { seguinte }\end{array}$ & $\begin{array}{l}\text { Tepe }[r] \\
\text { Fricativa palatoalveolar }\left[\int\right] \\
\text { Fricativa palatoalveolar }[3] \\
\text { Fricativas alveolares }[\mathrm{s}, \mathrm{z}] \\
\text { Nasais }[\mathrm{m}, \mathrm{n}] \\
\text { Laterais }[\mathrm{l}, \Lambda] \\
\text { Oclusivas }[\mathrm{p}, \mathrm{b}, \mathrm{t}, \mathrm{d}, \mathrm{k}, \mathrm{g}] \\
\text { Vogais }\end{array}$ & $\begin{array}{l}\text { Favorável em todos os estudos } \\
\text { Favorável em todos os estudos, com exceção de } \\
\text { Araújo (1999) que a considerou neutra em } \\
\text { relação ao ditongo [eI] } \\
\text { Favorável em todos os estudos, com exceção de } \\
\text { Araújo (1999) que a considerou desfavorável } \\
\text { em relação ao ditongo [e I] } \\
\text { Desfavorável em todos os estudos } \\
\text { Desfavorável em todos os estudos } \\
\text { Desfavorável em todos os estudos. } \\
\text { Desfavorável em todos os estudos. Somente } \\
\text { ocorre a monotongação na palavra manteiga } \\
\text { A vogal [a] foi considerada favorável no estudo } \\
\text { de Amaral (2005) em relação ao ditongo [eI]. }\end{array}$ \\
\hline Tonicidade & $\begin{array}{l}\text { Tônica } \\
\text { Átona }\end{array}$ & $\begin{array}{l}\text { Favorável para Araújo (1999) e Paiva (1996). } \\
\text { Favorável para Amaral (2005) e Silva (2004) - } \\
\text { sílabas pretônicas. }\end{array}$ \\
\hline $\begin{array}{l}\text { Status } \\
\text { morfológico }\end{array}$ & $\begin{array}{l}\text { Radical } \\
\text { Sufixo }\end{array}$ & $\begin{array}{l}\text { Favorável para Cabreira (1996) e Lopes (2002). } \\
\text { Favorável para Paiva (1996). }\end{array}$ \\
\hline Escolaridade & $\begin{array}{l}\text { Menos escolarizados } \\
\text { Mais escolarizados }\end{array}$ & $\begin{array}{l}\text { Em todos os estudos que consideraram a } \\
\text { variável escolaridade, esse fator foi favorecedor. } \\
\text { Em todos os estudos que consideraram a } \\
\text { variável escolaridade, esse fator foi inibidor. }\end{array}$ \\
\hline$\overline{\text { Idade }}$ & $\begin{array}{l}\text { Jovens } \\
\text { Velhos }\end{array}$ & $\begin{array}{l}\text { Em Amaral (2005), os mais jovens } \\
\text { monotongam mais. } \\
\text { Em Araújo (1999), os mais velhos favorecem a } \\
\text { monotongação. }\end{array}$ \\
\hline Outros & $\begin{array}{l}\text { Palavras comuns } \\
\text { Velocidade de fala } \\
\text { Posição do elemento } \\
\text { seguinte favorecedor } \\
\text { Classe de palavra } \\
\text { Extensão do vocábulo }\end{array}$ & $\begin{array}{l}\text { As palavras de uso mais corriqueiro favorecem o } \\
\text { fenômeno; variável considerada por Lopes (1999) } \\
\text { Velocidade rápida favorece a monotongação; variável } \\
\text { considerada por Araújo (1999) } \\
\text { Na sílaba seguinte, a monotongação é favorecida; na } \\
\text { mesma sílaba, é inibida; fator considerado por } \\
\text { Cabreira (1996) } \\
\text { Os não verbos favorecem a monotongação; variável } \\
\text { considerada por Amaral (2005) } \\
\text { Palavras monossilábicas desfavorecem o fenômeno; } \\
\text { variável considerada por Paiva (1996) }\end{array}$ \\
\hline
\end{tabular}




\section{TABELA 1}

Exemplos de itens lexicais frequentes e não frequentes com ditongos em contextos uniformes propícios e o número de monotongaçōes

\begin{tabular}{l|l|l}
\hline Palavra & Frequência de ocorrência & Monotongações \\
\hline Deixar e flexões & 222 & 220 \\
Dinheiro & 174 & 174 \\
Primeiro/a/as/os & 144 & 144 \\
Brincadeira/s & 54 & 53 \\
Embaixo & 50 & 50 \\
Baixo & 26 & 26 \\
Terceiro & 23 & 23 \\
Pedreiro & 12 & 11 \\
Caixa & 10 & 10 \\
Enfaixar e flexões & 7 & 7 \\
Apaixonar e flexões & 6 & 6 \\
Abaixo & 4 & 4 \\
Caixeiro & 2 & 2 \\
Solteirona & 3 & 2 \\
\hline
\end{tabular}

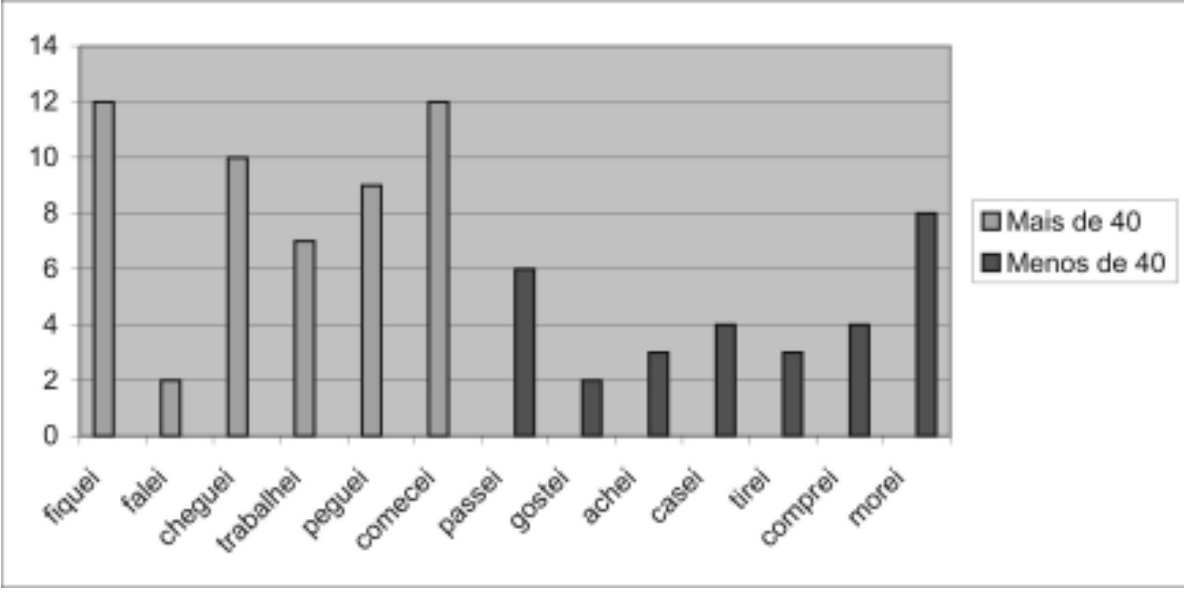

GRÁFICO 1 - Monotongações dos itens lexicais com ditongo [eI ] em sílabas abertas finais como desinência verbal 


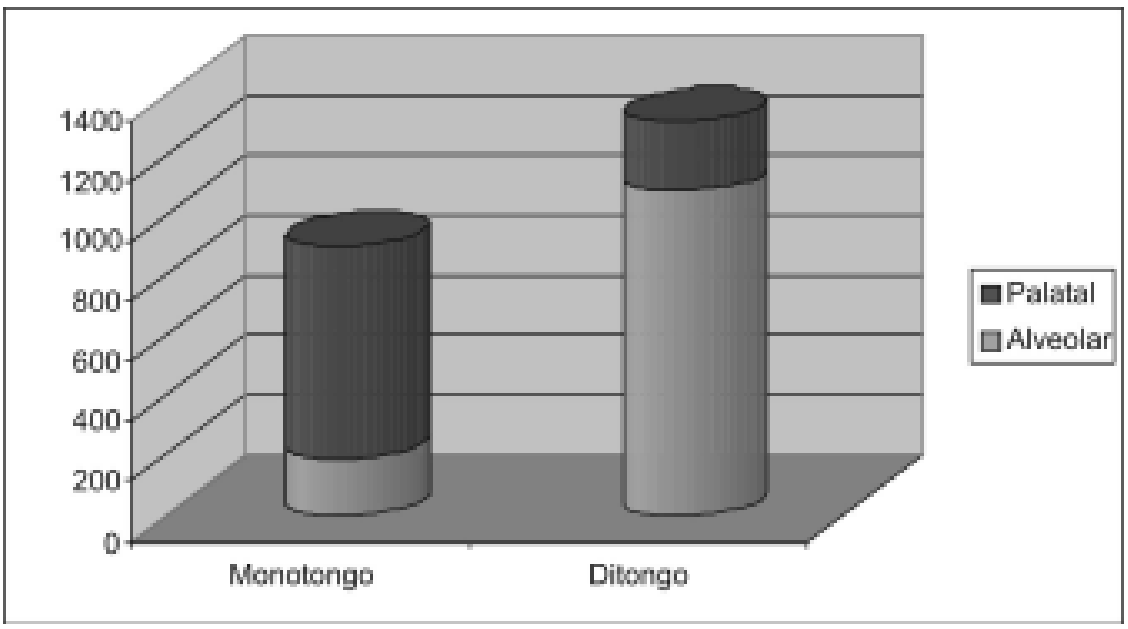

GRÁFICO 2 - Cruzamento dos casos de monotongação com os casos de palatalização

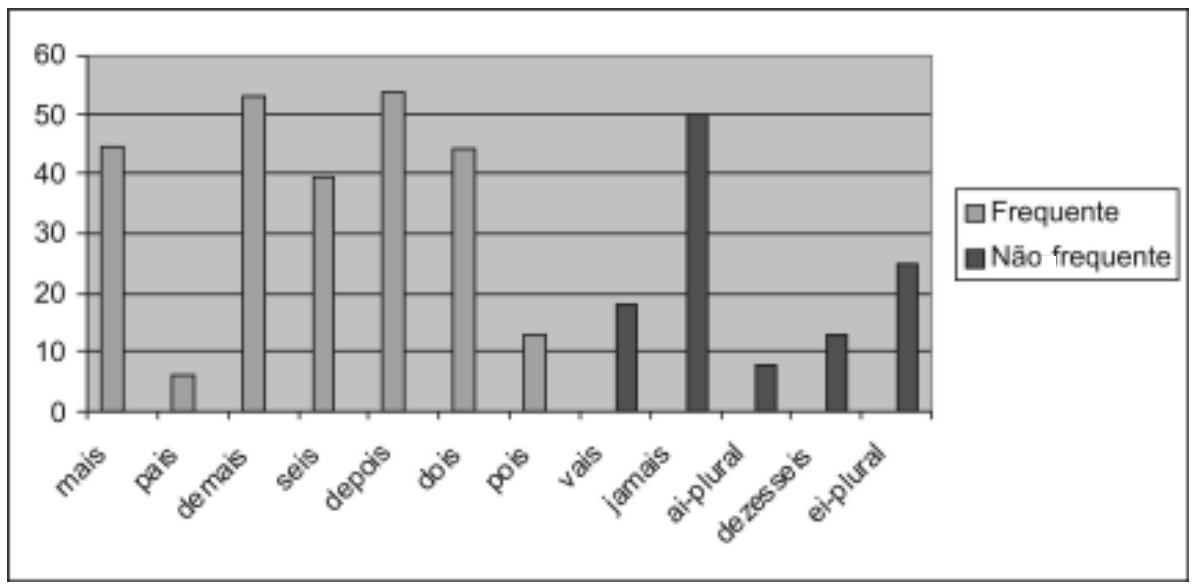

GRÁFICO 3 - Frequência de ocorrência e monotongações de itens lexicais com ditongos em sílabas fechadas

Submissão do artigo: 6/5/2011 Aprovação do artigo: 18/10/2011 